\title{
Coupling Relationship between Lithofacies and Brittleness of the Shale Oil Reservoir: A Case Study of the Shahejie Formation in the Raoyang Sag
}

\author{
Zhaojing Song, ${ }^{1,2}$ Junqian Li $\mathbb{D}^{1,2}$ Xiaoyan Li, ${ }^{3}$ Ketong Chen, ${ }^{3}$ Chengyun Wang, ${ }^{3}$ Peng Li, ${ }^{3}$ \\ Yongbo Wei, ${ }^{1,2}$ Rixin Zhao, ${ }^{1,2}$ Xiaocheng Wang, ${ }^{1,2}$ Shasha Zhang, ${ }^{3}$ Mengying Yan, \\ and Haiyan Geng ${ }^{3}$ \\ ${ }^{1}$ Shandong Provincial Key Laboratory of Deep Oil and Gas, Qingdao, Shandong 266580, China \\ ${ }^{2}$ School of Geosciences, China University of Petroleum (East China), Qingdao, Shandong 266580, China \\ ${ }^{3}$ Research Institute of Exploration and Development, PetroChina Huabei Oilfield Company, Renqiu, Hebei 062550, China \\ Correspondence should be addressed to Junqian Li; lijunqian@upc.edu.cn
}

Received 17 November 2021; Revised 16 December 2021; Accepted 17 December 2021; Published 15 January 2022

Academic Editor: Afshin Davarpanah

Copyright (C) 2022 Zhaojing Song et al. This is an open access article distributed under the Creative Commons Attribution License, which permits unrestricted use, distribution, and reproduction in any medium, provided the original work is properly cited.

Analyzing the characteristics of rock brittleness in low-permeability mudstone and shale (MS) formations is imperative for efficient hydraulic fracturing stimulation. Rock brittleness depends on the mineral composition, organic matter abundance, and bedding structure. Based on the MS from Shahejie Formation mineral composition (clay mineral, felsic mineral, and calcareous mineral contents), total organic content, and bedding structure (laminated, laminar, and massive), six types of lithofacies were identified: clay-rich MS, felsic-rich MS, calcareous-rich MS, clay MS, felsic MS, and calcareous MS. The quartz, feldspar, calcite, and dolomite of the Shahejie Formation are brittle minerals. Consequently, lithofacies with high felsic and calcareous mineral contents are more brittle. In addition, laminated and laminar MS are also conducive to hydraulic fracturing. Therefore, laminated, organic-rich, and calcareous-rich MS are the dominant lithofacies for hydraulic fracturing in the Shahejie Formation. The lithofacies and brittleness index were predicted by the response characteristics between mineral compositions and logging curves. The 3521-3552 m section of well B11x is dominated by calcareous-rich MS with developed laminae, representing a favorable section for hydraulic fracturing. Fragile minerals and oil are widely developed in the lower part of the lower 1st member of the Shahejie Formation $\left(\mathrm{Es}_{1}{ }^{\mathrm{L}}\right)$ in the southwestern part of Zhaohuangzhuang-Suning, where hydraulic fracturing can be used to increase shale oil production.

\section{Introduction}

Abundant continental shale oil resources are the focus of current unconventional oil development and research [1-3]. Continental fine-grained sedimentary rocks (CFSR) are primarily developed in lake environments. Owing to the variations in the sedimentary environment, the mineral composition, structure, and organic content of CFSR are highly heterogeneous, which is not conducive to selecting fracturing intervals [4-8]. One of the vital construction factors affecting the recoverability of shale oil is hydraulic fracturing treatment [9-12]. Fracability is a measure of the difficulty of a shale reservoir to be effectively reformed and indicates whether a reservoir may produce a larger reformed volume by fracturing $[13,14]$. Chong et al. [15] proposed the concept of using brittleness index (BI) as a norm to evaluate the fracturing ability of shale reservoirs. Fracability is enhanced when the BI of mudstone and shale (MS) is higher.

The brittleness of MS can be evaluated based on the mechanical properties or mineral composition of the rock. Young's modulus and Poisson's ratio are critical mechanical properties that indicate shale brittleness. Higher Young's modulus and lower Poisson's ratio indicate higher shale brittleness, and the shale will be more amenable to hydraulic fracturing treatment [16, 17]. There are two different methods for determining the mechanical properties of rocks: 
static and dynamic. In the static method, a certain pressure is applied to the rock under laboratory conditions to analyze the stress-strain relationship of the rock, thereby calculating Young's modulus and Poisson's ratio. In the dynamic method, the mechanical properties of rocks are determined using sonic wave propagation through the rock. The mechanical properties of a continuous distribution are obtained through logging data, including sonic wave and rock density data. They define the brittle minerals, which is crucial for calculating the BI using the mineral composition method. Based on the mineral composition characteristics of the Barnett Shale, Jarvie et al. [18] considered quartz to be the major brittle mineral. Wang and Gale [19] suggested that dolomite is also a brittle mineral. Additionally, some scholars consider that quartz, feldspar, calcite, and dolomite are brittle minerals in shales with complex mineral compositions [20-22].

Static parameters produce several changes in the sample-loading history; however, the mechanical properties of rock under formation conditions can be simulated by applying different forces to the sample. The rock mechanical properties (Young's modulus, Poisson's ratio, bulk modulus, and shear modulus) and rock strength (compressive strength, tensile strength, and shear strength) at any formation depth can be easily obtained from sonic logging data. However, shear wave velocity cannot be obtained in most old wells because it is usually obtained from long spacing sonic logging or multipole array logging [23]. Mineral components can be obtained via methods such as whole-rock mineral X-ray diffraction (XRD), energy dispersive spectroscopy, and element capture spectroscopy logging. A practical method can combine the above methods for maximum advantage. The mechanical properties of rock minerals vary considerably. However, by analyzing the relationship between different minerals and mechanical properties, minerals can be divided into brittle and nonbrittle ones. Subsequently, a BI calculation formula can be derived based on the mineral components. This formula has guiding research in target areas with few research data.

There are several significant differences between marine shale and CFSR [24-28]. CFSR is strongly affected by the sediment source and sedimentary environments [29, 30]. Consequently, CFSR is highly heterogeneous, which is primarily manifested in the mineral types, rock compositions, structural characteristics, pore space, organic matter (OM) characteristics, and hydrocarbon mobility [31-36]. Some scholars have studied this issue. Jiang et al. [25,37] proposed a classification scheme for eastern China, which is based on total organic content (TOC), carbonate content, and clay minerals, with TOC contents of $2 \%$ and $4 \%$ as the boundaries. The rocks are then divided into three categories: low TOC, medium TOC, and high TOC. Additionally, 50\% carbonate and clay minerals are used as boundary, and thus, six subcategories are established. Chen et al. [38] analyzed the mineral composition, bedding structure, OM abundance, color, and other contaminants in the Dongying Sag and found that the content of mixed fine-grained sedimentary rocks was $>60 \%$. Using this definition, the rock was subdi- vided into 17 lithofacies based on Jiang et al.'s classification scheme [25].

The brittleness characteristics of MS are closely associated with rock characteristics such as mineral composition, bedding structure, and TOC, which can be reflected by lithofacies [39]. Different lithofacies have different brittleness characteristics, and analysis of the coupling relationship between lithofacies and brittleness has great significance for selecting hydraulic fracturing intervals. Research on the shale interval of the $\mathrm{Es}_{1}{ }^{\mathrm{L}}$ in the Raoyang Sag is relatively limited, and data are insufficient. Therefore, this study first classified the lithofacies of the rocks in $\mathrm{Es}_{1}{ }^{\mathrm{L}}$. The classification was based on mineral composition, sedimentary structure, and TOC. Subsequently, the mechanical properties of the rock were obtained through triaxial mechanical experiments. Brittle minerals were defined by analyzing the relationships between different minerals and mechanical parameters of the rocks, and the BI was calculated. The dominant lithofacies were selected by analyzing the brittleness characteristics of the different lithofacies. Finally, hydraulic fracturing intervals conducive to shale oil development were selected.

\section{Geological Setting}

The Raoyang Sag, with an area of approximately $5280 \mathrm{~km}^{2}$, is located in the central region of the Jizhong Depression, Bohai Bay Basin (Figure 1). The sag has the richest hydrocarbon resources in the depression [30, 40, 41]. High-quality hydrocarbon source rocks of the $\mathrm{Es}_{1}{ }_{1}^{\mathrm{L}}$ and 3rd member of the Shahejie Formation, which are an essential material basis for the formation of shale oil, are developed in a semideep and deep lacustrine sedimentary environment [30,42].

\section{Samples and Methods}

3.1. Samples. The $\mathrm{Es}_{1}{ }^{\mathrm{L}}$ in the Raoyang Sag has a large area of continuously distributed organic-rich shale with high OM content. Most areas have entered the oil generation window $[30,40,42]$. In this study, an experimental analysis was performed on 99 MS samples with different secondary structures from $\mathrm{Es}_{1}{ }^{\mathrm{L}}$. The experiment included four types of tests: TOC measurement, Rock-Eval pyrolysis analysis, thin section identification, and XRD analysis.

3.2. TOC and Rock-Eval Pyrolysis Analyses. The TOC and Rock-Eval pyrolysis analyses were conducted at the Key Laboratory of Deep Oil and Gas at the China University of Petroleum (East China). For estimating TOC, samples were first crushed to an approximate mesh size of 100 and then reacted with $5 \%$ diluted hydrochloric acid to remove inorganic carbon. After oven-drying at $80^{\circ} \mathrm{C}(5 \%)$, the TOC content was determined using an Elab-TOC/E2000 analyzer. Rock-Eval pyrolysis analysis required crushing the sample to an approximate mesh size of 100 and then heating the sample from 300 to $600^{\circ} \mathrm{C}\left(25^{\circ} \mathrm{C} / \mathrm{min}\right)$ under anaerobic conditions with nitrogen as the carrier gas in a YQ-VIIA RockEval rock pyrometer. The hydrocarbons and carbon dioxide 


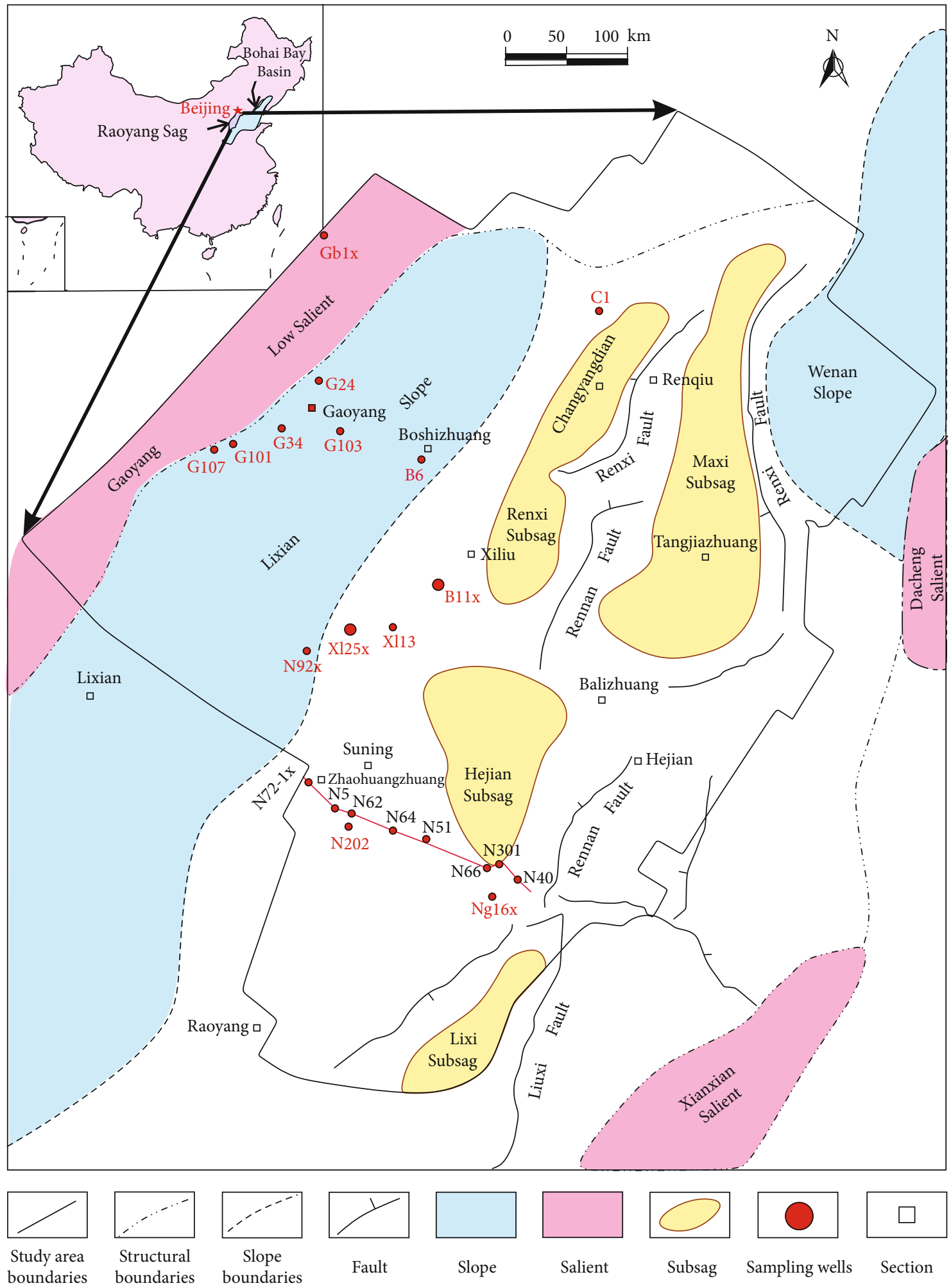

Figure 1: Structural map and well locations of the Raoyang Sag (modified after [30]).

emissions released from the rock were quantified using a flame ionization detector and thermal conductivity detector. The measured parameters were the free hydrocarbon content when vaporized at a temperature of $300^{\circ} \mathrm{C}\left(S_{1}\right)$, residual hydrocarbon generation potential when the temperature was between 300 and $600^{\circ} \mathrm{C}\left(S_{2}\right)$, and temperature of the maximum pyrolysis yield $\left(T_{\max }\right)$.

3.3. XRD Tests. XRD tests were performed on the 99 samples to quantitatively analyze their relative mineral contents. All 


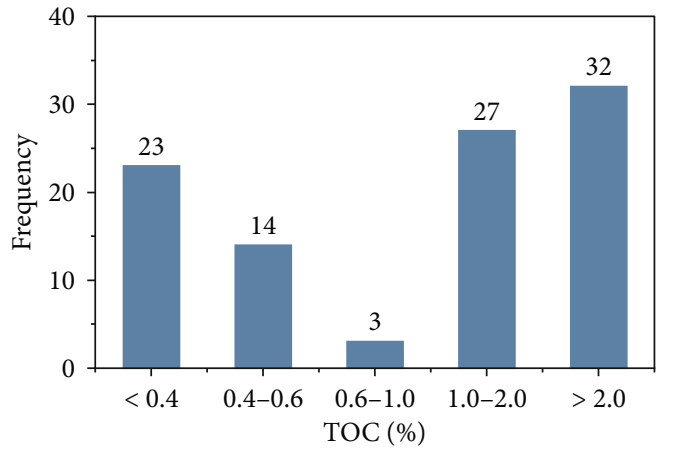

(a)

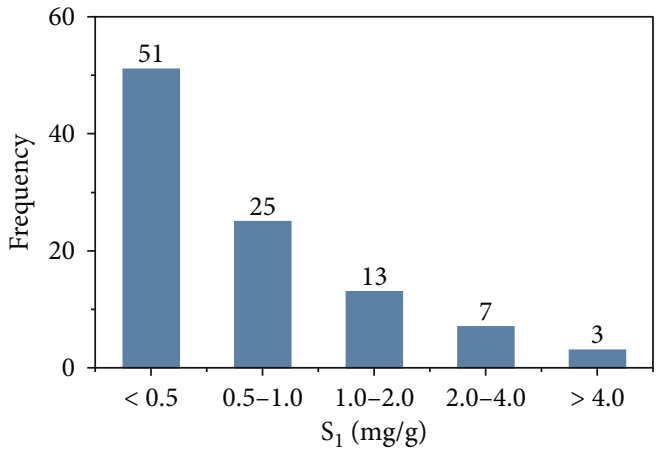

(b)

FIgURE 2: Distribution frequency diagrams of (a) TOC and (b) $S_{1}$ in the $\mathrm{Es}_{1}{ }^{\mathrm{L}}$ of the Raoyang Sag.

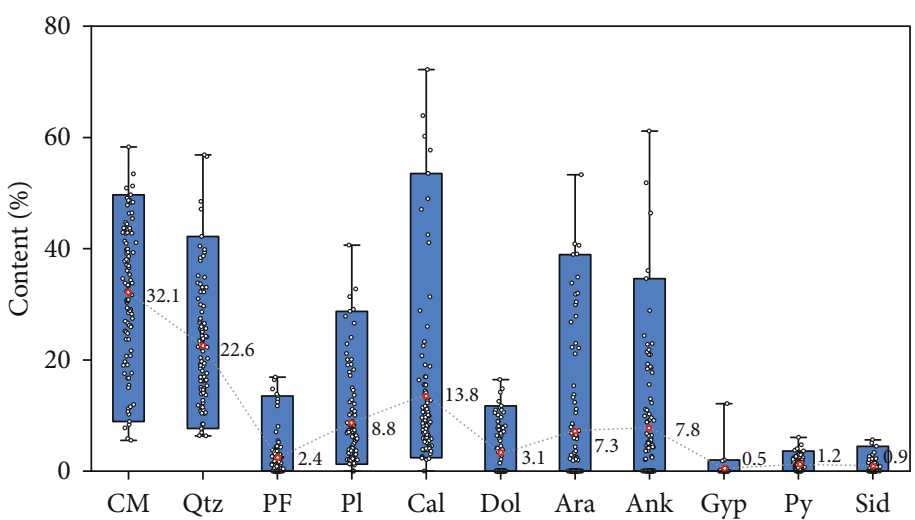

(a)

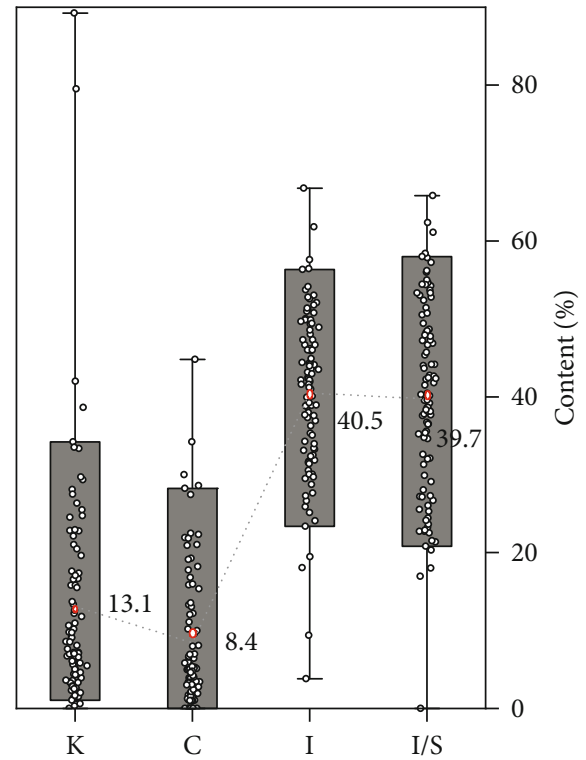

(b)

Figure 3: (a) Inorganic mineral and (b) clay mineral contents of $\mathrm{Es}_{1}{ }_{1}^{\mathrm{L}}$ in the Raoyang Sag. CM: clay minerals; Qtz: quartz; PF: potash feldspar; PI: plagioclase; Cal: calcite; Dol: dolomite; Ara: aragonite; Gyp: gypsum; Py: pyrite; and Sid: siderite.

samples used for XRD analysis were powders with a particle size of $<40 \mu \mathrm{m}$. The analytical instrument used was a Panalytical X'Pert PRO MPD X-ray diffractometer with $\mathrm{Cu}$ $\mathrm{K} \alpha$ radiation $(40 \mathrm{kV}, 40 \mathrm{~mA})$ at a scanning speed of $2^{\circ} / \mathrm{min}$ and testing angle range of $5^{\circ}-90^{\circ}$.

3.4. Mechanical Experiment. Six rock samples from the study area were drilled as regular core plugs with a diameter of approximately $2.5 \mathrm{~cm}$ using an SK-5625A cycling CNC diamond wire cutting machine. In natural underground conditions, the rock is always under in situ stress and mostly in a state of stress from three axes. Therefore, when hydraulic fracturing is designed, it is necessary to consider the deformation characteristics of rocks under a certain confining pressure. In this test, a conventional triaxial compression experiment was performed on a plugged specimen. First, the specimen was placed in an autoclave, and lateral pressure (confining pressure) was then applied to the core. Finally,

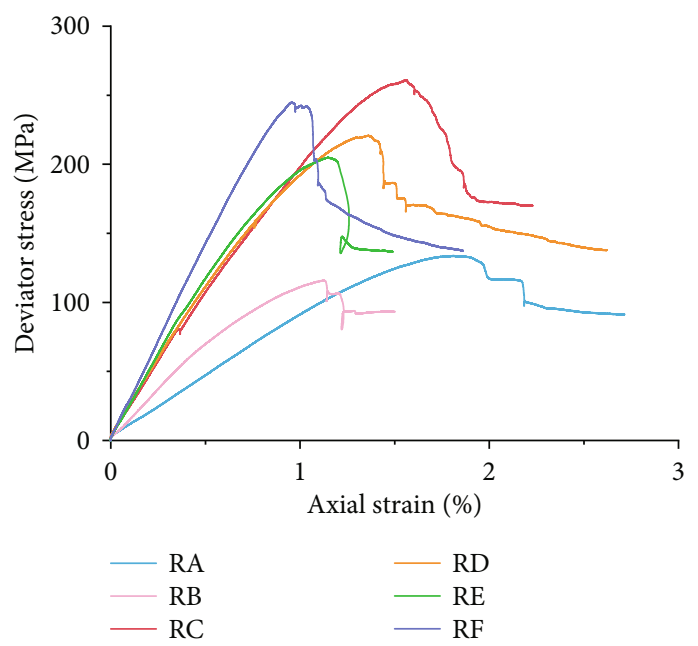

FIGURE 4: Stress-strain curves of mudstone and shale. 
TABLE 1: Classification of rock types in the $\mathrm{Es}_{1}{ }^{\mathrm{L}}$ of the Raoyang Sag.

\begin{tabular}{lcccc}
\hline Codename & Rock type & Clay & Mineral content (\%) & Felsic \\
\hline A & Clay-rich MS & $\geq 50$ & $<50$ & $<2$ \\
B & Felsic-rich MS & $<50$ & $\geq 50$ & $<50$ \\
C & Calcareous-rich MS & $<50$ & $<50$ & $\geq 50$ \\
D & Clay MS & $33 \sim 50$ & $<$ Clay mineral content & $<$ Clay mineral content \\
E & Felsic MS & $<$ Felsic mineral content & $33 \sim 50$ & $<$ Felsic mineral content \\
F & Calcareous MS & $<$ Calcareous mineral content & $<$ Calcareous mineral content & $33-50$ \\
\hline
\end{tabular}

axial stress was applied to the core through the hydraulic cylinder of the press. The confining pressure was maintained at $20 \mathrm{MPa}$ throughout the experiment, and the axial pressure was gradually increased until the specimen was destroyed.

\section{Results}

The TOC values of the MS samples ranged from $0.09 \%$ to $5.71 \%$, with an average of $1.36 \%$. Among the samples, 59 had a TOC value $>1.00 \%$ (Figure $2(\mathrm{a})$ ). The $S_{1}$ value of the 99 samples ranged from $0.01 \%$ to $6.27 \%$ (average of $0.78 \%$ ) (Figure 2(b)). Clay minerals and quartz were the major minerals in $\mathrm{Es}_{1}{ }^{\mathrm{L}}$ in the Raoyang Sag, with average contents of $31.80 \%$ (range: $1.30 \%-58.30 \%$ ) and $22.30 \%$ (range: $1.00 \%-$ $56.90 \%$ ) (Figure $3(\mathrm{a})$ ). The clay minerals in $\mathrm{Es}_{1}{ }^{\mathrm{L}}$ primarily comprised of illite (average: $40.50 \%$ ) and illite-smectite mixed layer clay (average: $39.70 \%$ ), followed by kaolinite and chlorite (Figure 3(b)). Other minerals also had various degrees of development (Figure 3(a)).

Figure 4 shows the stress-strain relationships of the six specimens under a confining pressure of $20 \mathrm{MPa}$. Based on the calculated results, Young's modulus ranged from 9.04 to $28.07 \mathrm{GPa}$, with an average of $19.40 \mathrm{GPa}$. Poisson's ratio was approximately 0.2 . The distribution of Poisson's ratio was relatively narrow with only small perturbations. Young's modulus values varied significantly among the different samples. Young's modulus was the major factor affecting the mechanical characteristics of the rock in the study area.

\section{Discussion}

\subsection{Types and Characteristics of Lithofacies}

5.1.1. Lithofacies Types. In this study, the minerals of the $\mathrm{Es}_{1}{ }^{\mathrm{L}}$ were divided into four categories: clay minerals, felsic minerals (quartz and feldspar), calcareous minerals (calcite, aragonite, dolomite, and iron dolomite), and other minerals (pyrite, siderite, and gypsum) according to the properties of each mineral in the MS. The MS were classified based on its mineral content [43]. MS with a clay mineral content $>50 \%$ were defined as clay-rich MS. When clay minerals were the most abundant minerals, with a content between $33 \%$ and $50 \%$, the MS were categorized as clay MS. Felsic-rich MS, felsic MS, calcareous-rich MS, and calcareous MS were also similarly defined (Table 1). The sedimentary structure of the $\mathrm{Es}_{1}{ }^{\mathrm{L}}$ was also categorized. According to the degree of bedding development, $\mathrm{MS}$ of the $\mathrm{Es}_{1}{ }^{\mathrm{L}}$ were approximately divided into laminated (bedding thickness $<1 \mathrm{~mm}$ ), laminar ( $1 \mathrm{~mm}<$ bedding thickness $<50 \mathrm{~cm}$ ), and massive (bedding thickness $>50 \mathrm{~cm}$ ) structures. The rock with laminated or laminar structure was classified as shale, and the rock with massive structure was called mudstone.

In previous lithofacies classification schemes, the OM boundaries have typically been determined based on subjective experience. However, this method is controversial because of the differences in geological conditions. By analyzing the relationship between shale oil content and TOC, Lu et al. [44] classified shale oil and gas resources into three levels: scattered (ineffective), inefficient, and enriched resources. TOC can be used as a grading standard that is important for the study of shale oil. The oil content of the samples from $\mathrm{Es}_{1}{ }_{1}^{\mathrm{L}}$ exhibited the characteristics of a tripartite division with increases in TOC value and chloroform bitumen "A" (Figure 5). The TOC classification limits were determined to be $0.6 \%$ and $1.7 \%$. Based on these classification boundaries, rocks were divided into three types: organic-rich MS (TOC $>1.7 \%)$, organic-medium MS $(0.6 \%<$ TOC $<$ $1.7 \%)$, and organic-poor MS (TOC $<0.6 \%)$.

In summary, the classification rules for the shale in the $\mathrm{Es}_{1}{ }^{\mathrm{L}}$ in the Raoyang Sag include the following three aspects: structure (laminated, laminar, or massive), characteristics of OM contents (organic-rich, organic-medium, or organicpoor), and rock type (such as clay-rich shale) (Table 1). The lithofacies classification results of the 99 shale samples in the study area are shown in Figure 6.

5.1.2. Lithofacies Characteristics. The rock types of the 99 samples from the $\mathrm{Es}_{1}{ }^{\mathrm{L}}$ were primarily clay MS (35.35\%) and calcareous-rich MS (23.23\%), followed by felsic MS (21.21\%) and calcareous MS (11.11\%) (Figure 7). As shown in Figure 6, the rock type, bedding structure, and OM characteristics have a specific relationship. In calcareous-rich MS, calcareous minerals, siliceous minerals, clay minerals, and OM typically occurred in alternate bands (Figures 8(a) and $8(\mathrm{~b})$ ), or calcareous minerals, clay minerals, and OM occurred in alternate bands (Figures $8(\mathrm{c})$ and $8(\mathrm{~d})$ ). The TOC ranged from $0.54 \%$ to $5.07 \%$, with an average of $2.45 \%$. The calcareous MS and calcareous-rich MS exhibited the same bedding characteristics (Figures $8(\mathrm{e})$ and $8(\mathrm{f})$ ). However, clay mineral bands and siliceous mineral bands appeared more frequently in the calcareous MS, and the OM content was slightly lower. Within the clay MS, with an average TOC of $2.44 \%$, organic-rich MS were observed, which can be divided into two types: well-developed bedding 


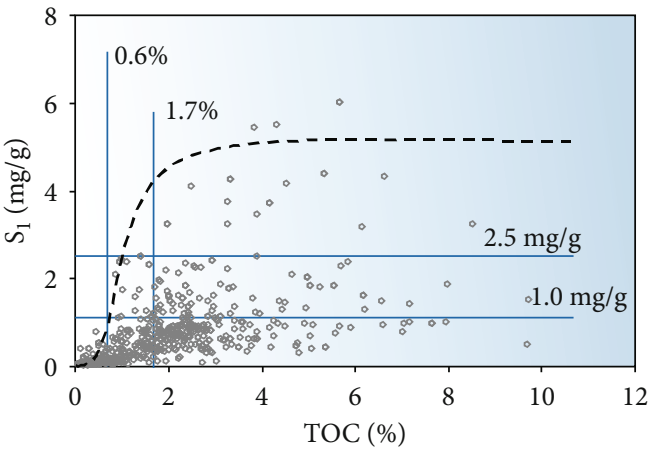

(a)

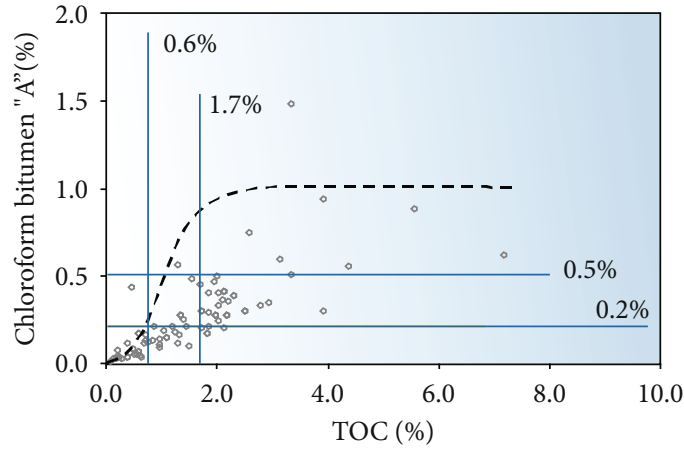

(b)

Figure 5: Relationships between (a) TOC and $S_{1}$ and (b) TOC and chloroform bitumen "A" in the Es ${ }_{1}{ }^{\mathrm{L}}$ of the Raoyang Sag (data from the PetroChina Huabei Oilfield Exploration Development Research Institute).

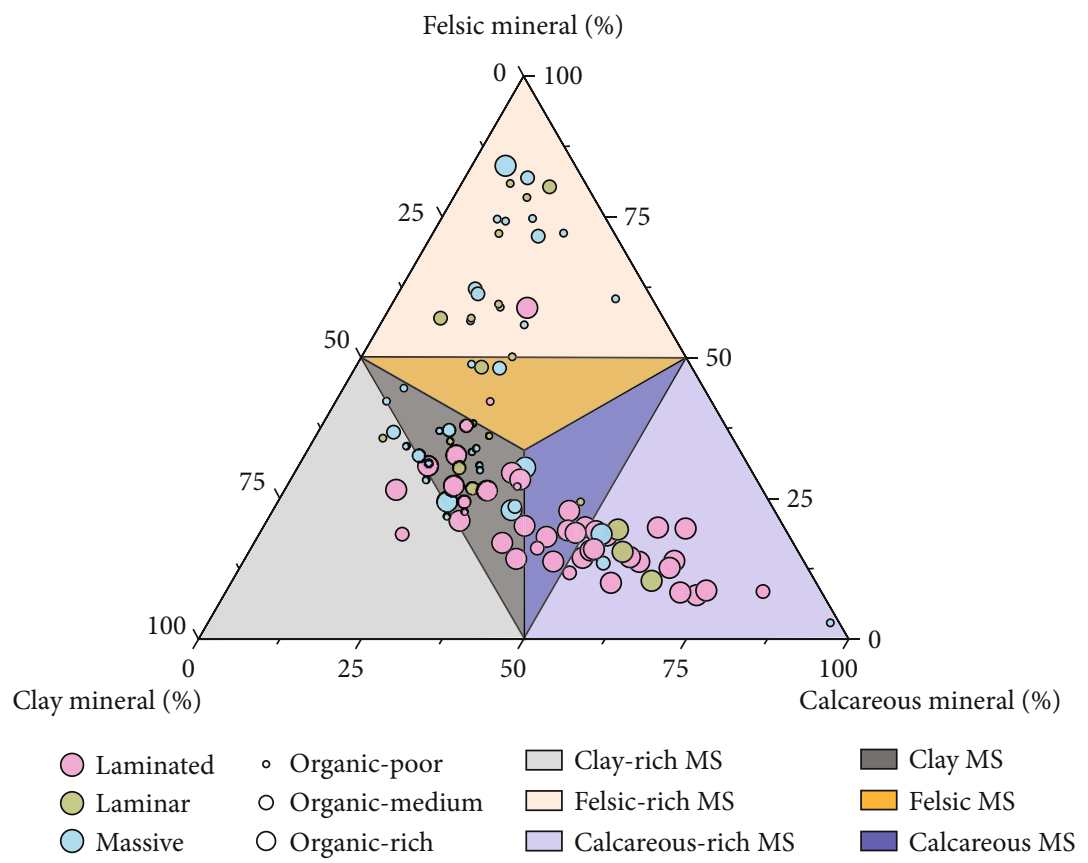

FIGURE 6: Lithofacies types of the mudstone and shale (MS) in the $\mathrm{Es}_{1}{ }^{\mathrm{L}}$ of the Raoyang Sag.

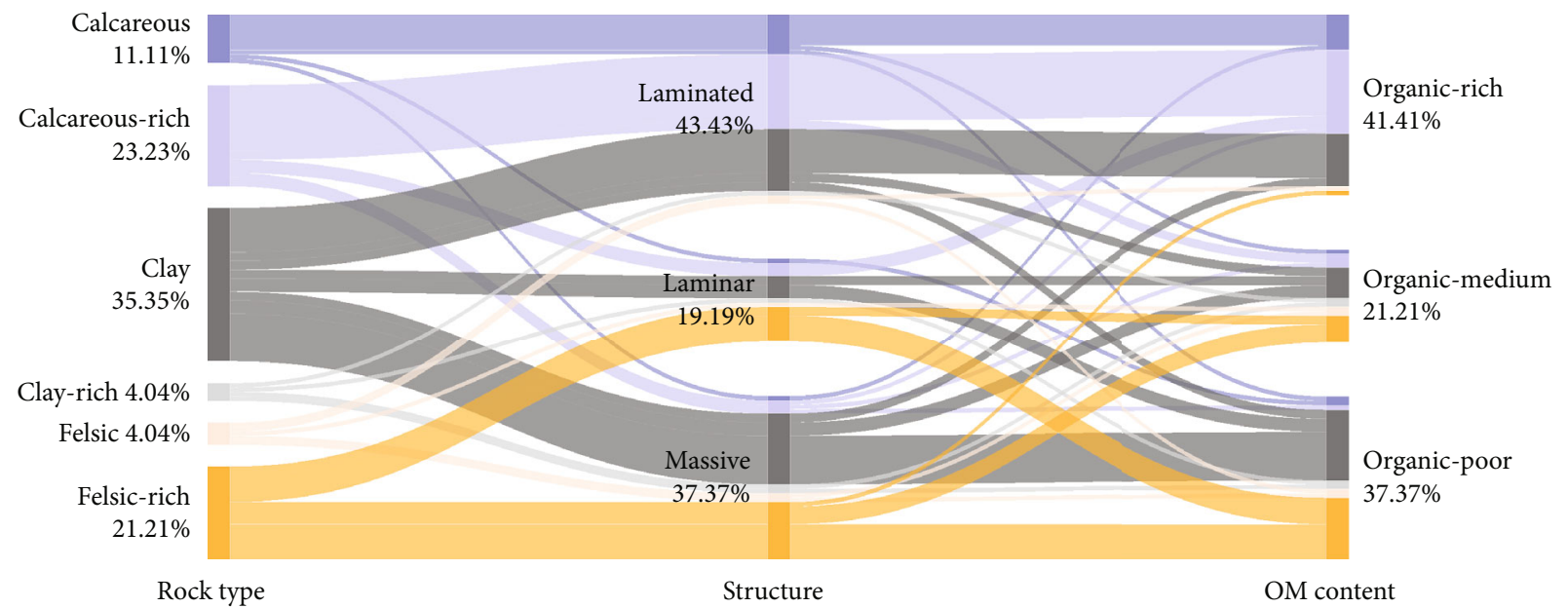

FIGURE 7: Correspondence between the rock types, bedding structure, and OM characteristics of the MS in the Es ${ }_{1}^{\mathrm{L}}$. 


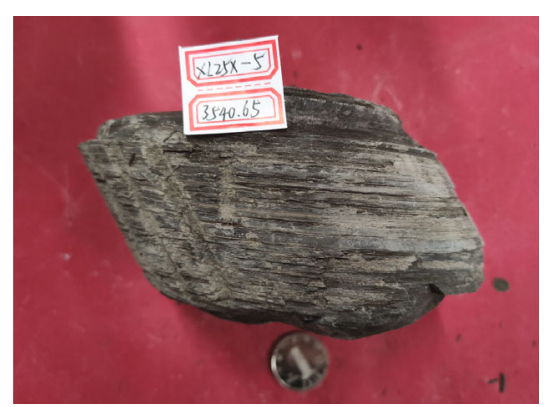

(a)

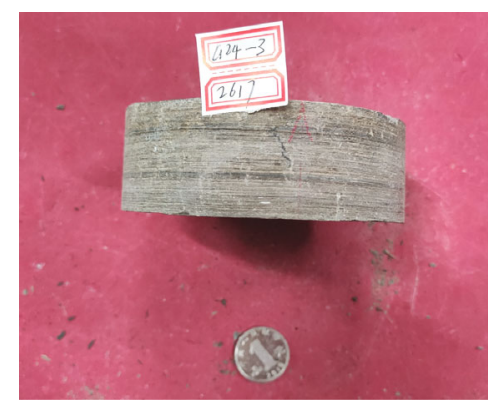

(c)

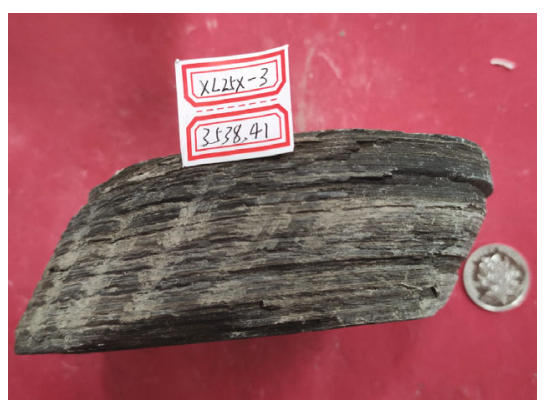

(e)

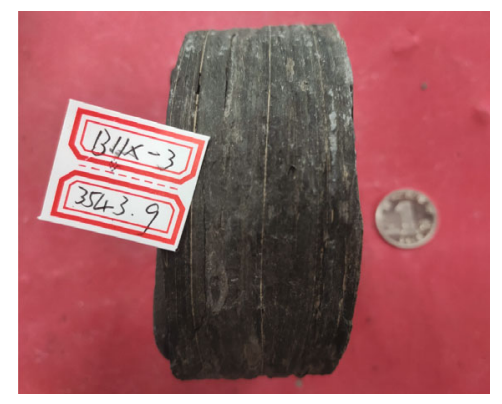

(g)

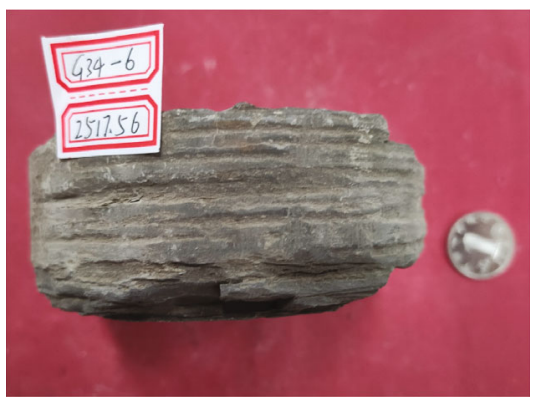

(i)

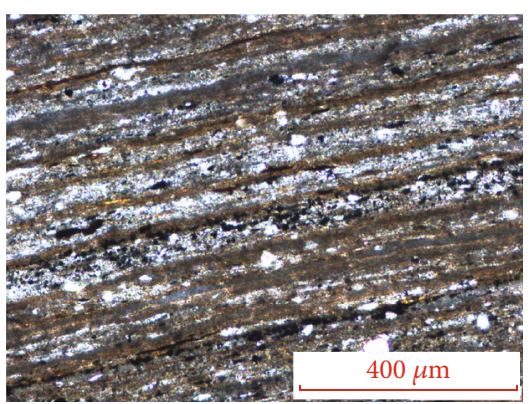

(b)

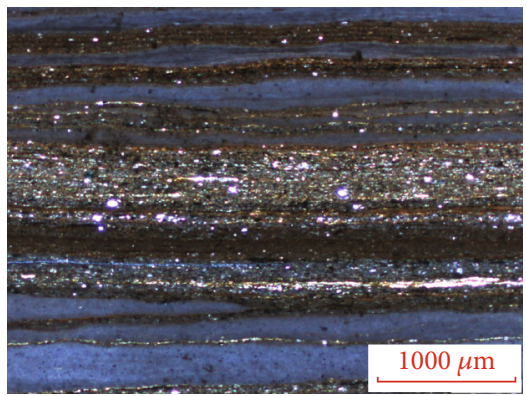

(d)

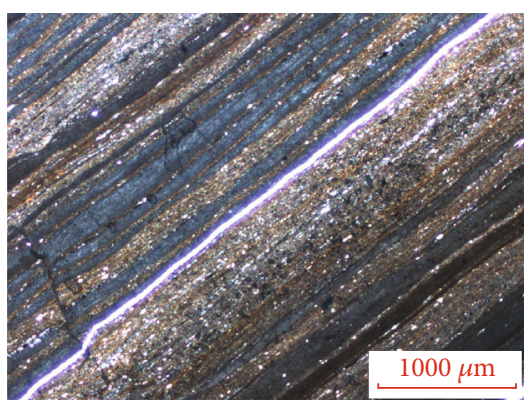

(f)

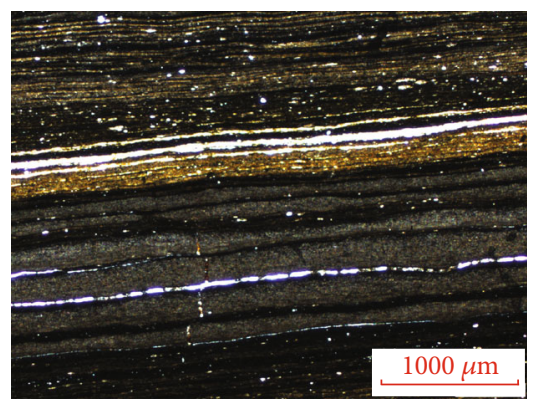

(h)

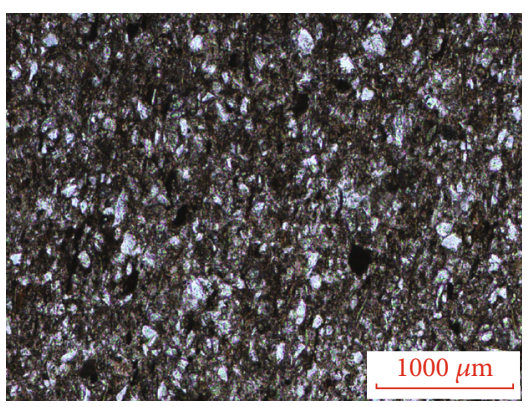

(j)

Figure 8: Continued. 


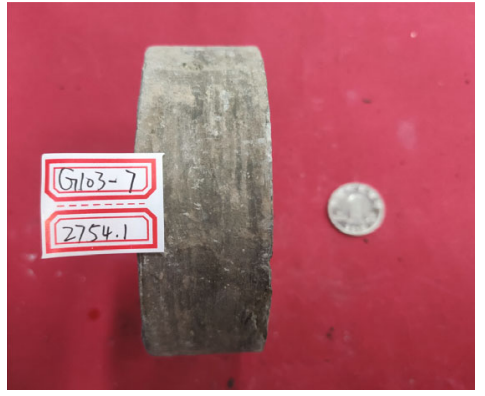

(k)

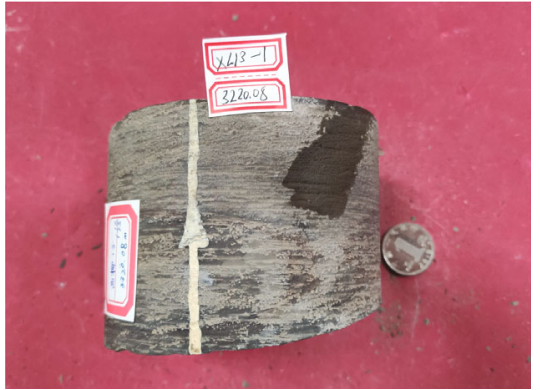

(m)

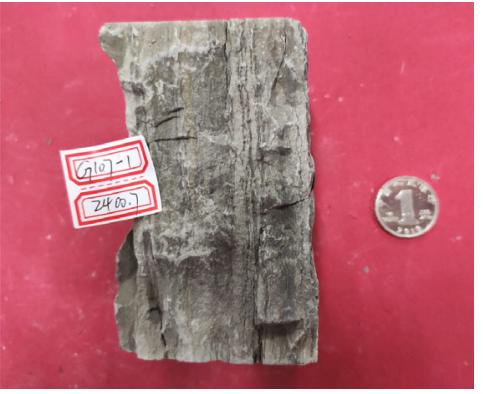

(o)

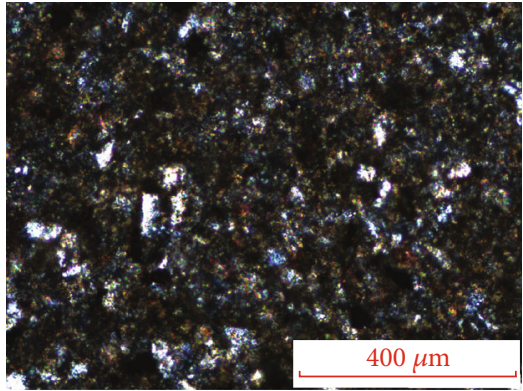

(l)

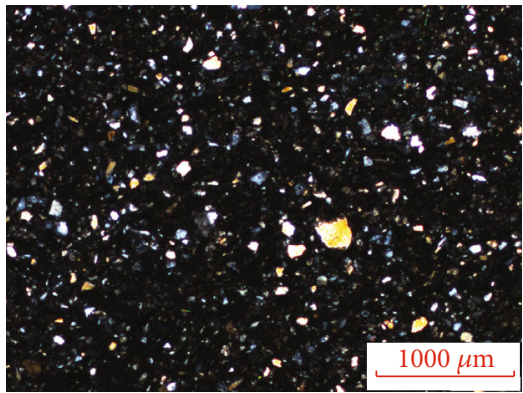

(n)

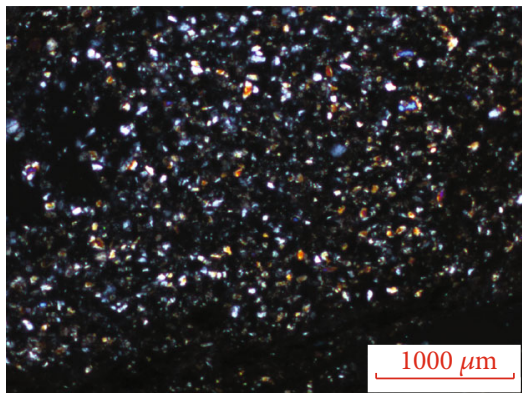

(p)

Figure 8: (a, b) Calcareous-rich MS, well XL25x, $3540.65 \mathrm{~m}$; (c, d) calcareous-rich MS, well G24, 2617.00 m; (e, f) calcareous MS, well XL25x, 3538.41 m; (g, h) clay MS, well B11x, 3543.90 m; (i, j) clay MS, well G34, 2517.56 m; (k, l) clay-rich MS, well G103, 2754.10 m; $(\mathrm{m}, \mathrm{n})$ felsic MS, well XL13, $3220.08 \mathrm{~m}$; (o, p) felsic-rich MS, well G107, $2400.70 \mathrm{~m}$.

type and underdeveloped bedding type. The beddingdeveloped clay MS had a ternary laminar structure. The ternary laminar layer comprised alternately distributed calcareous minerals, felsic minerals, clay minerals, and $\mathrm{OM}$ (Figures $8(\mathrm{~g})$ and $8(\mathrm{~h})$ ). The clay MS with underdeveloped bedding were dominated by massive structures (Figures 8(i) and $8(\mathrm{j})$ ). The former was dominated by organic-rich MS, whereas the latter was mostly organic-poor MS with OM content ranging from $0.09 \%$ to $1.60 \%$ (average: $0.58 \%$ ). The clayrich MS mostly had a massive structure and low OM content (Figures $8(\mathrm{k})$ and $8(\mathrm{l})$ ). The felsic-rich MS (Figures $8(\mathrm{~m})$ and 8(n)) and felsic MS (Figures 8(o) and 8(p)) were dominated by siliceous minerals, followed by clay minerals. Laminae were not developed, and most of them are organic-poor MS or organic-medium MS types.

\subsection{Brittleness Evaluation}

5.2.1. Brittleness Evaluation Based on Mineral Composition. Young's modulus $(E)$ is a physical quantity that reflects the ability of a solid material to resist deformation. It is expressed as the slope of the stress and strain in a uniaxial rock mechanics experiments [45-47].

$$
E=\frac{\Delta \sigma_{\mathrm{a}}}{\Delta \varepsilon_{\mathrm{a}}},
$$

where $\Delta \sigma_{\mathrm{a}}$ is the axial stress increment and $\Delta \varepsilon_{\mathrm{a}}$ is the axial strain increment.

Poisson's ratio $(v)$, also called the transverse deformation coefficient, refers to the ratio of the absolute value of the transverse positive strain to the positive axial strain when the material is under tension or compression in one direction.

$$
v=\frac{\Delta \varepsilon_{\mathrm{r}}}{\Delta \varepsilon_{\mathrm{a}}}
$$


TABLE 2: Composition characteristics of mudstone and shale.

\begin{tabular}{lcccccccccc}
\hline Serial number & Qtz (\%) & PF (\%) & Pl (\%) & Cal (\%) & Dol (\%) & Sid (\%) & Py (\%) & Ank (\%) & Ara (\%) & CM (\%) \\
\hline RA & 24.1 & 5.0 & 11.0 & 12.3 & 0.0 & 0.0 & 0.4 & 2.2 & 7.2 & 36.9 \\
RB & 22.3 & 2.1 & 7.4 & 10.0 & 7.2 & 2.2 & 0.6 & 0.0 & 0.0 & 48.4 \\
RC & 10.3 & 0.0 & 1.9 & 10.5 & 0.0 & 0.0 & 0.7 & 33.2 & 23.5 & 17.8 \\
RD & 10.3 & 0.0 & 1.9 & 10.5 & 0.0 & 0.0 & 0.7 & 33.2 & 23.5 & 17.8 \\
RE & 32.2 & 4.5 & 10.8 & 15.5 & 6.4 & 1.3 & 0.3 & 0.0 & 0.0 & 29.2 \\
RF & 15.2 & 2.4 & 0.0 & 61.1 & 0.0 & 0.0 & 0.0 & 4.2 & 0.0 & 17.0 \\
\hline
\end{tabular}

$\mathrm{RA}$ and RE are felsic MS; RB is clay MS; and RC, RD, and RF are calcareous-rich MS.

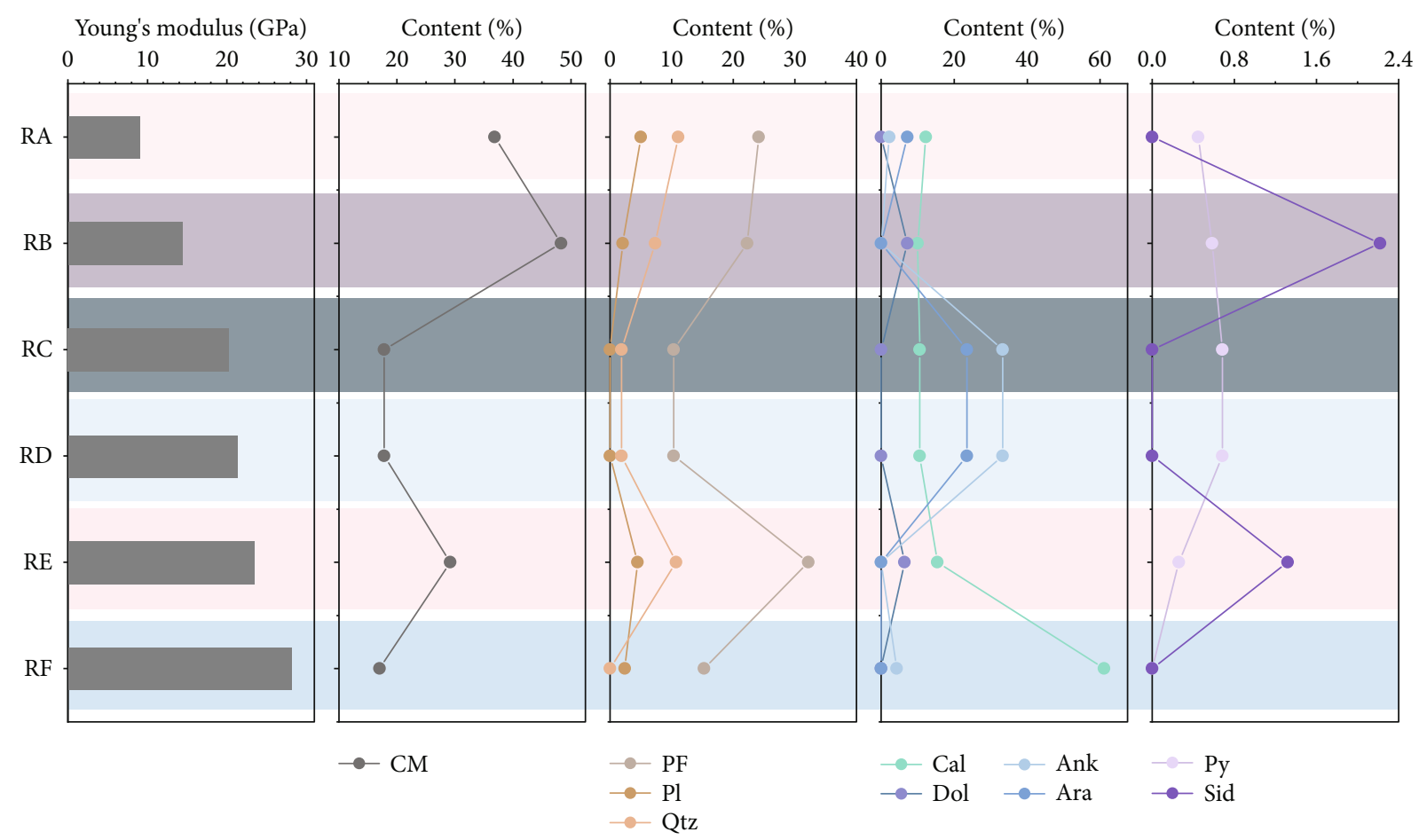

FIGURE 9: Characteristics of mineralogical composition and Young's modulus for the different samples.

where $\Delta \varepsilon_{\mathrm{a}}$ is the axial strain increment and $\Delta \varepsilon_{\mathrm{r}}$ is the radial strain increment.

The compositions of the six samples are listed in Table 2.

(1) Impact of Material Composition on Brittleness. The mechanical properties (Young's modulus) of different minerals are extremely different and are closely related to the nature of the minerals [43]. Even for the same mineral, the contribution to brittleness in different regions may have completely opposite effects. The calcite in the Dongying Sag in eastern China has a degradative effect on the shale brittleness [43]. However, the calcite in the Barnett shale of North Texas is an essential contributor to effective reservoir fracturing [48]. Therefore, the contribution of the various minerals to brittleness cannot be generalized. Brittle minerals require specific analyses in different regions. The influence of the different minerals on Young's modulus was analyzed comprehensively in the Shahejie Formation (Figure 9).
Figure 10 shows that clay minerals are negatively correlated with Young's modulus (Figure 10(a)) and positively correlated with calcareous minerals (Figure 10(b)). Three samples, RC, RD, and RF, had low felsic and high calcareous mineral contents. The respective calcareous mineral contents occupying the central part of the rock mineral composition (Figure 10(c)) were 67.28\%, 67.28\%, and 65.32\% and significantly contributed to rock frangibility. For these three samples, the contribution of felsic minerals to brittleness was limited. Nevertheless, felsic minerals did make have a positive contribution to shale brittleness (Figure 10(d)). In addition, the shale oil development interval commonly had a relatively high OM content, and therefore, the impact of $\mathrm{OM}$ on the brittleness of the MS cannot be ignored. Eliyahu et al. [49] revealed that Young's modulus of OM is less than that of inorganic minerals. Furthermore, OM typically occupied the micronanoscale pore spaces between particles, thereby reducing the overall shale brittleness. The trend shown in Figure 10(f) is consistent with the aforementioned 


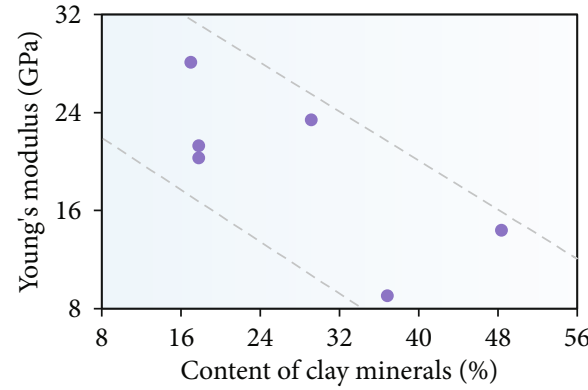

(a)

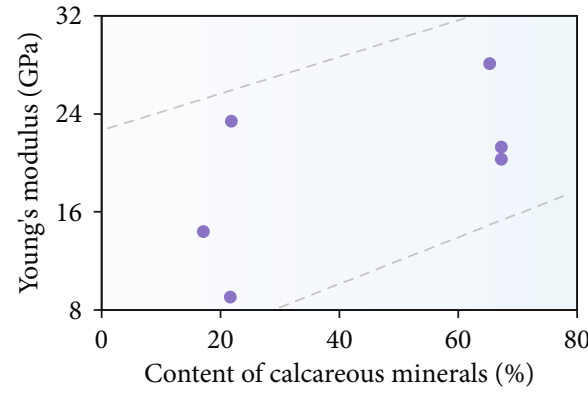

(c)

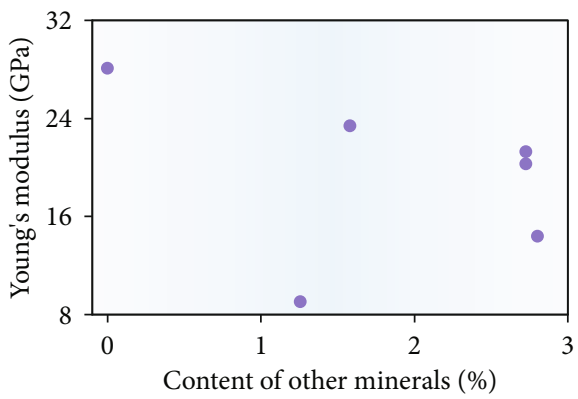

(e)

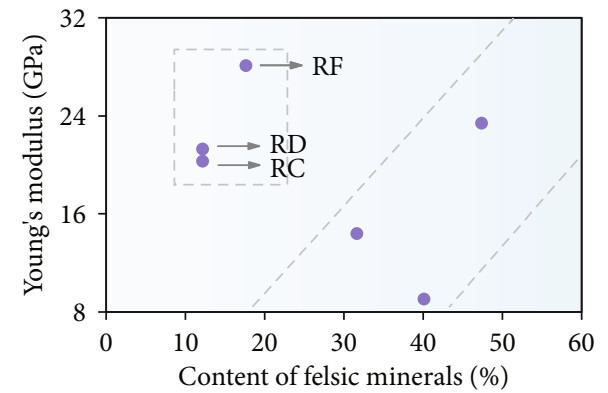

(b)

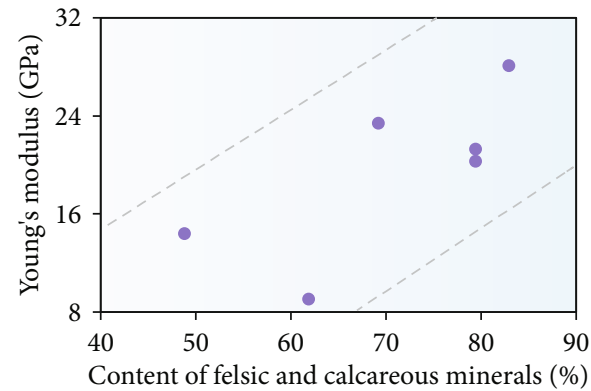

(d)

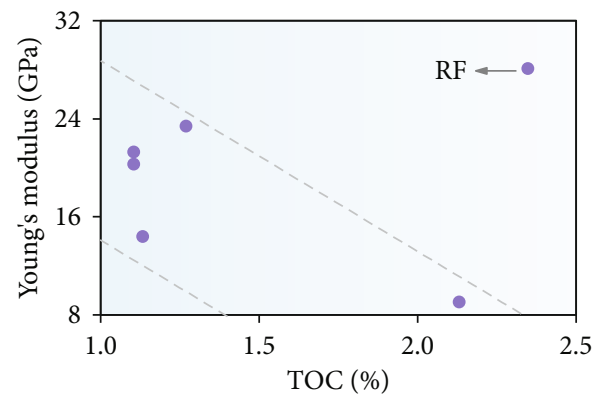

(f)

Figure 10: Relationship of Young's modulus of mudstone and shale with (a) clay, (b) felsic, (c) calcareous, (d) felsic and calcareous minerals, (e) other minerals, and (f) TOC.

research results. The content of other minerals was low, resulting in only a small influence on the rock brittleness (Figure 10(e)).

(2) Impact of the Bedding Structure on Brittleness. Rock is cemented by various mineral crystals and contains cracks, joints, and other internal defects [50-52]. The bedding surface of shale has an essential influence on fracturing, particularly when the bedding surface is different from the loading direction [53,54]. The RC and RD samples were obtained from the same shale but in different directions. The RC sample was perpendicular to the bedding, and the $\mathrm{RD}$ sample was parallel to the bedding. As shown in Figure 8, the rupture strength and Young's modulus of the RD sample were lower than those of the RC sample. Fracturing parallel to the bedding plane is more conducive to the reformation of shale.

5.2.2. BI Based on Mineralogy. Referring to previous evaluation methods [18] and considering them along with the min- eralogical characteristics of the Shahejie Formation, clay minerals and TOC are negatively correlated with brittleness, and felsic minerals and calcareous minerals are positively correlated. Thus, the formula for calculating the BI of the material composition can be expressed as follows:

$$
B=\frac{C_{\mathrm{fel}}+C_{\mathrm{ca}}}{C_{\mathrm{cl}}+C_{\mathrm{fel}}+C_{\mathrm{ca}}+C_{\mathrm{TOC}}}
$$

where $B$ is the brittleness index and $C_{\mathrm{cl}}, C_{\mathrm{fel}}, C_{\mathrm{ca}}$, and $C_{\mathrm{TOC}}$ are the clay mineral content, felsic mineral content, calcareous mineral content, and TOC, respectively.

This equation can more conveniently evaluate the brittleness characteristics of shale oil reservoirs in locations with sparse research data. This equation can help in selecting an interval favorable for hydraulic fracturing.

5.2.3. Brittleness Characteristics of Lithofacies. Clay minerals are unfavorable for shale oil, principally because of two aspects. On the one hand, clay minerals are plastic. They 


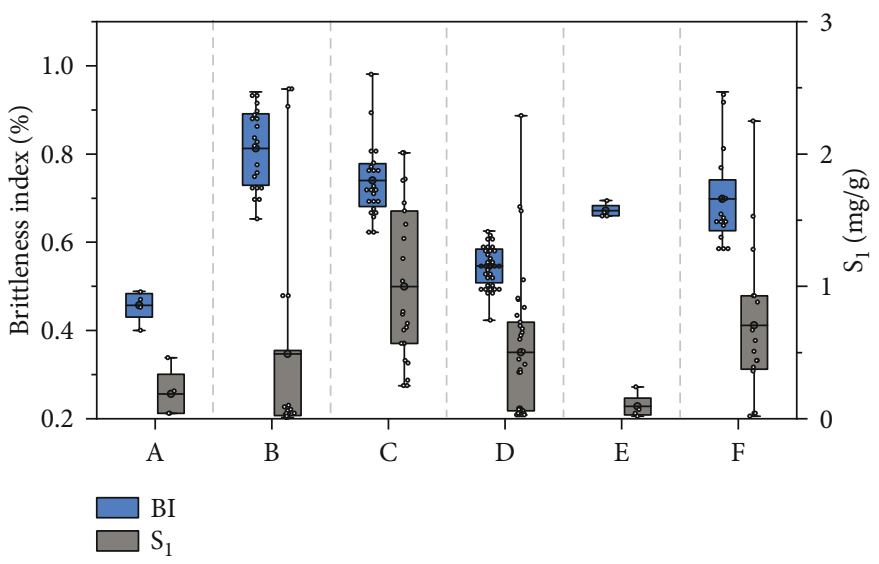

Figure 11: Brittleness index and $S_{1}$ of the different lithofacies.

TABLE 3: Correlation analysis of clay, felsic, and calcareous mineral contents and logging curve for well B11x.

\begin{tabular}{lccccccccc}
\hline Mineral composition & CAL & SP & GR & AC & CNL & DEN & R04 & R4 & R25 \\
\hline Clay minerals & 0.41 & -0.29 & -0.33 & 0.02 & 0.37 & -0.41 & -0.55 & -0.43 & -0.50 \\
Felsic minerals & 0.48 & -0.31 & -0.41 & 0.14 & 0.39 & -0.44 & -0.48 & -0.54 & -0.59 \\
Calcareous minerals & -0.46 & 0.33 & 0.39 & -0.07 & -0.38 & 0.44 & 0.60 & 0.50 & 0.57 \\
\hline
\end{tabular}
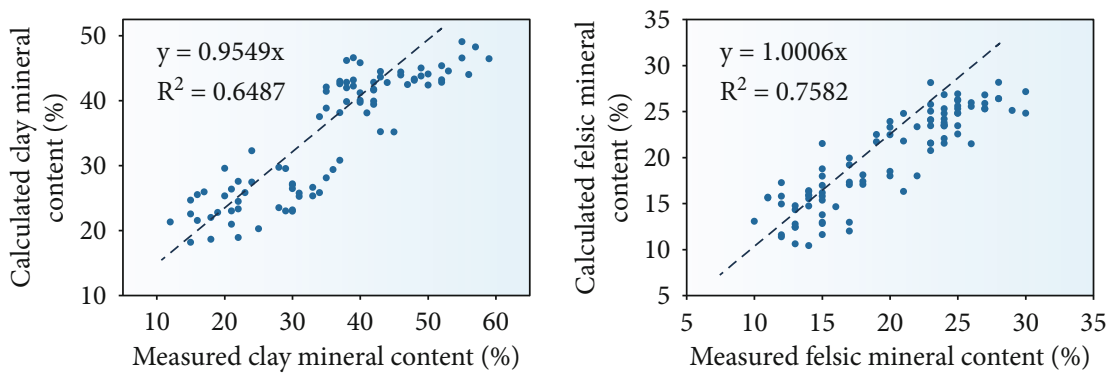

(a)
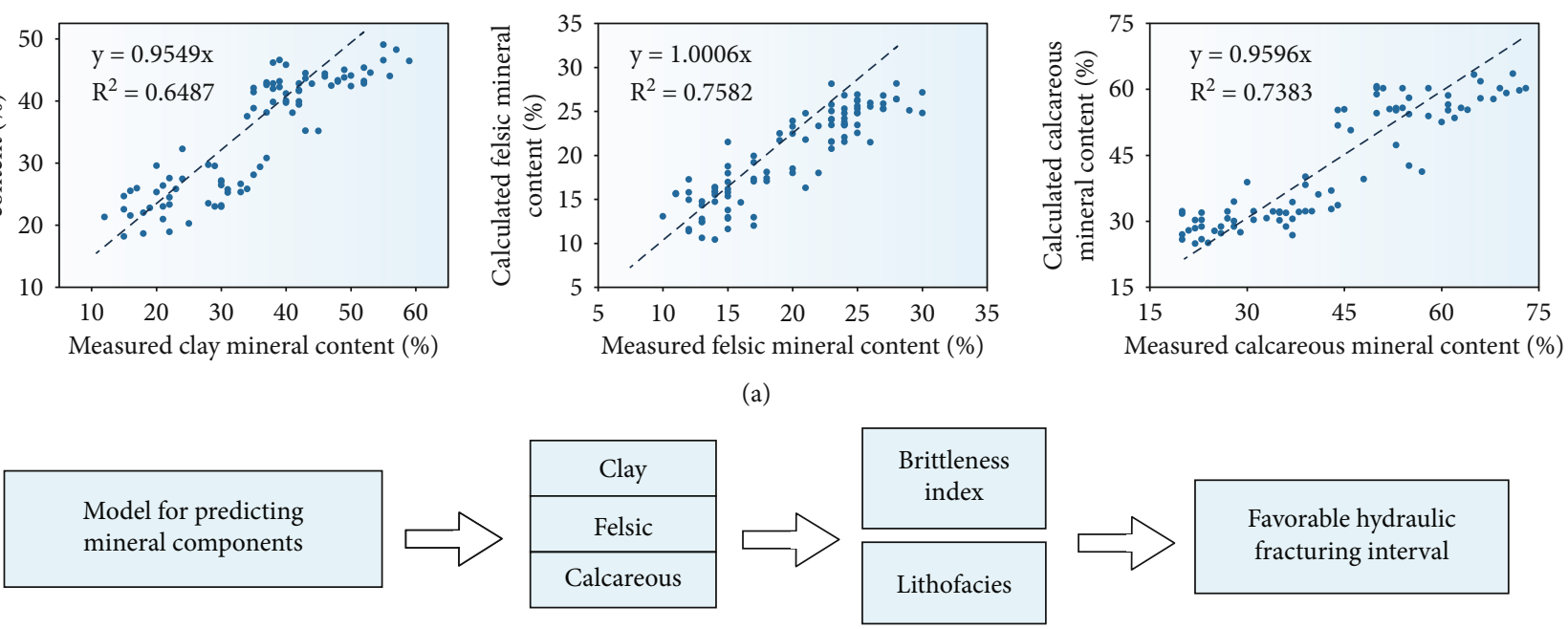

(b)

FIGURE 12: Establishment and application process of the mineral prediction model.

react with water during hydraulic fracturing, thereby causing the formation to collapse [55]. The clay-rich shale contains many clay minerals, and majority of it has massive structure. These are the reasons for its low brittleness. In contrast, the brittleness of the clay shale is greater than that of the clayrich shale. The content of brittle minerals is higher, and some clay shales have developed bedding. These factors are all favorable to increase.

Sufficient oil and gas contents are essential for the development of unconventional oil and gas reservoirs [56]. After establishing this, the next step is to improve the original permeability of the shale through fracturing [57]. The shales with a high content of calcareous and felsic minerals were brittle (Figure 11). However, the calcareous-rich MS and cal- careous MS, which are the dominant lithofacies for hydraulic fracturing, tended to have laminar structures with high $S_{1}$ and well-developed pore spaces. In contrast, the felsic-rich MS and felsic MS were relatively poor lithofacies, with low $S_{1}$ and block structures. Although the clay mineral content of the laminar clay shale was slightly higher, the developed bedding and high $S_{1}$ caused it to be a secondary favorable lithofacies (Figure 11).

\subsection{Establish a Mineral Component Calculation Model Based on Logging Evaluation}

5.3.1. Establishment of the Model. The back propagation (BP) neural network is a multilayer feedforward neural 
B11x

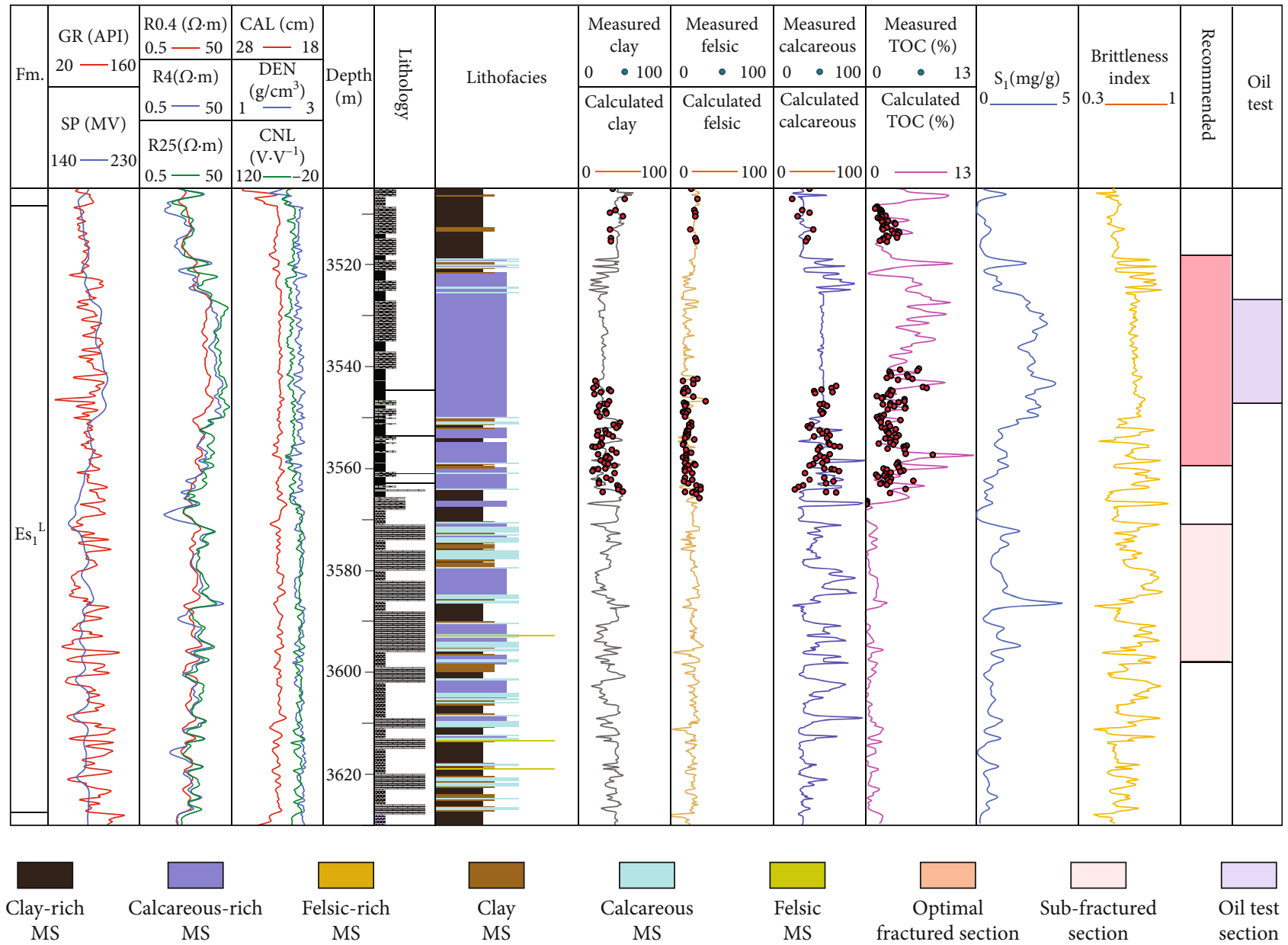

FIGURE 13: Comprehensive evaluation of longitudinal fractured section in well B11x.

network trained by the error backpropagation algorithm, comprising an input layer, output layer, and hidden layer $[58,59]$. It has self-learning ability, particularly promotion, generalization, and self-adaptive ability and is one of the most widely used neural network models. It can learn and store many input and output pattern mapping relationships without revealing the mathematical equations describing these mapping relationships in advance [59]. The learning process of the BP neural network involves two parts: forward propagation processing and back propagation processing. In the forward propagation process, the input layer set is processed layer by layer from the input layer through the hidden layer and then transmitted to the output layer. The state of each neuron layer only affects the state of the next neuron layer. If the desired output layer cannot be obtained, the output is transferred to the back propagation. At this time, the error signal propagates from the output layer to the input layer. It adjusts the connection weights of the layers and biases of the neurons of each layer along the way so that the error signal becomes continuously smaller. The basic principle of the BP neural network for predicting mineral components is to find a mapping relationship by continuously modifying the network weights and correction thresh- old until a satisfactory accuracy is obtained [59-61]. In this study, the input data were the screened logging curves, and the output data were mineral components.

Mineral components can be easily obtained from logging curves [62]. The relationships between different mineral components and conventional logging curves were analyzed. Afterward, the BP neural network algorithm was used to establish logging evaluation models for felsic, calcareous, and clay minerals. Finally, the inorganic mineral content was predicted. Taking well B11x in the Xiliu area of the Raoyang Sag as an example, the mineral contents were obtained via XRD analysis. First, the core data must be subjected to homing in with depth and matched with the corresponding logging curve. Conventional logging curves include lithology log (natural gamma log, spontaneous potential log, and caliper log), porosity log (acoustic time difference, density logging, and neutron log), and resistivity log (deep resistivity, medium resistivity, and shallow resistivity).

Different logging curves have different logging characteristics for various mineral types. For different types of minerals, logging curves with more significant correlation coefficients should be selected for core depth homing and logging modeling. The correlation analysis results of the 
Brittleness index

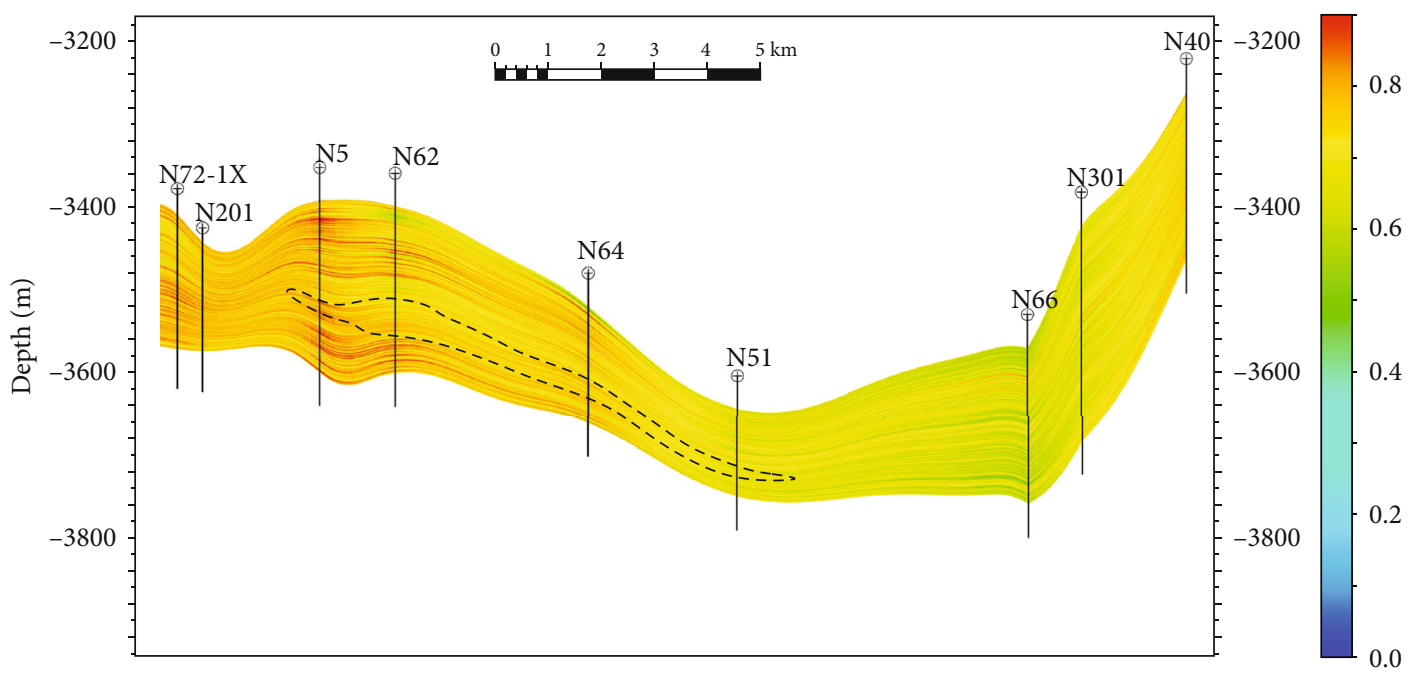

(a)

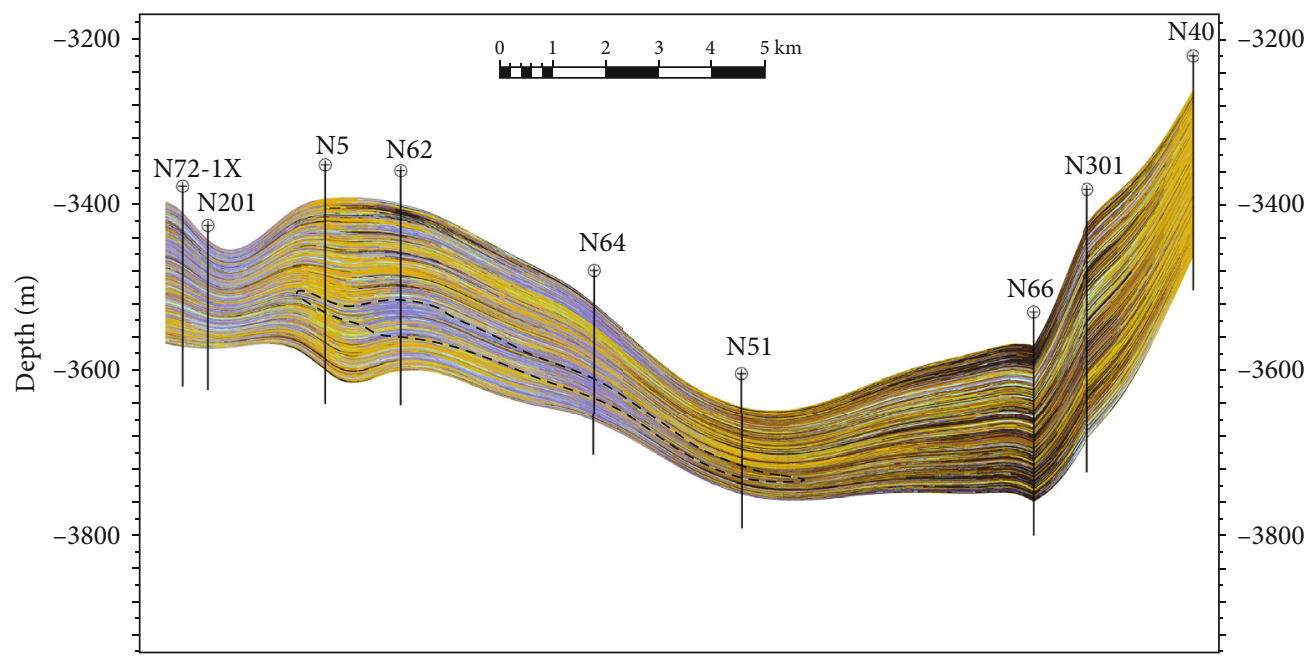

Lithofacies

Clay-rich shale

Calcareous-rich shale

Felsic-rich shale $\square$ Felsic shale

$\square$ Clay shale

$\square$ Calcareous shale

(b)

Figure 14: Continued. 


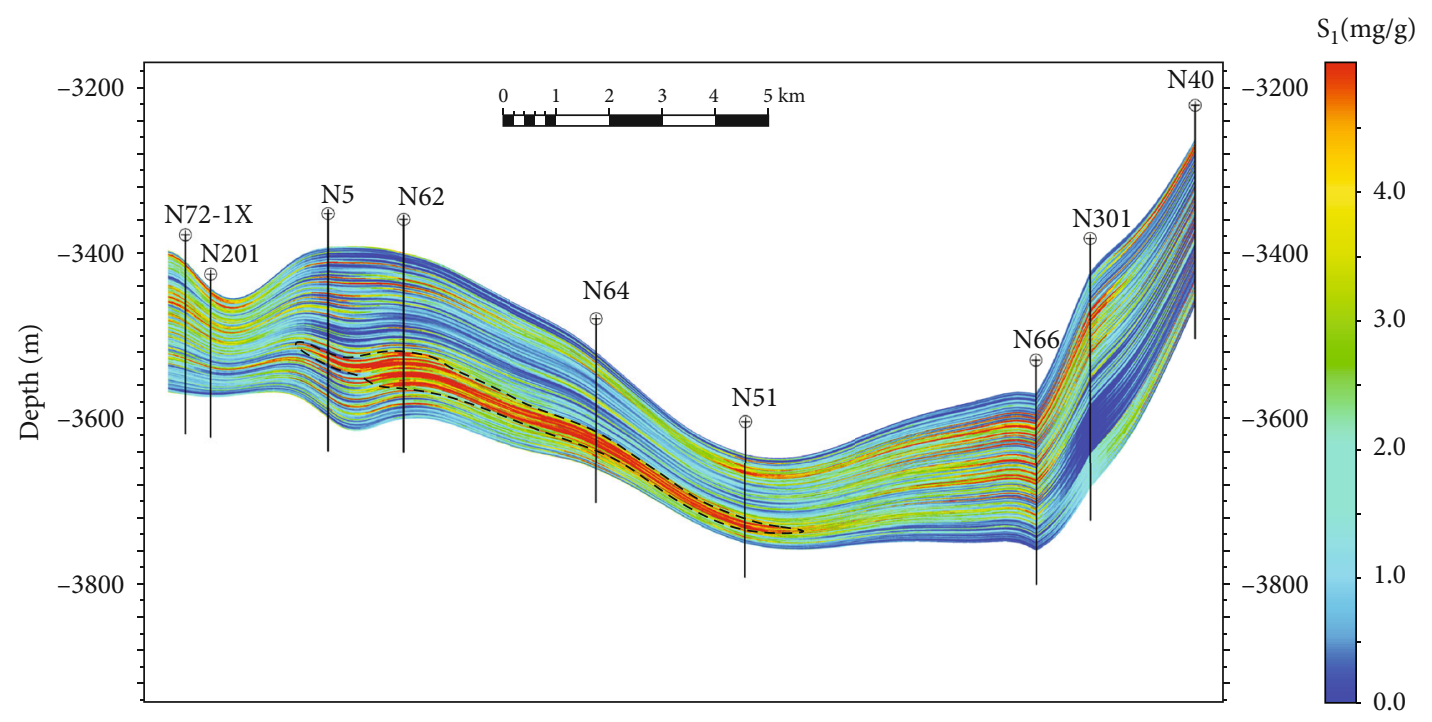

(c)

Figure 14: Profile connected by wells showing the (a) brittleness index, (b) lithofacies, and (c) $S_{1}$.

measured values of various minerals and the normalized values of the logging curves are presented in Table 3. The BP neural network algorithm was used to calculate the continuous distributions of felsic, calcareous, and clay minerals in the $\mathrm{Es}_{1}{ }^{\mathrm{L}}$ of well B11x. The results showed that the calculated value of the mineral composition in well B11x had a high correlation with the measured value (Figure 12(a)). The calculation model of minerals based on the BP neural network can better predict the continuous distribution of MS minerals in the longitudinal direction (Figure 13).

5.3.2. Application. Figure 12(b) shows that the established mineral component prediction model predicts the mineral component contents. Subsequently, the lithofacies are divided based on the established lithofacies division scheme. The distribution position of facies favorable to fracturing are determined, and the hydraulic fracturing interval is finally selected.

The lithofacies in well B11x were dominated by calcareous-rich MS and clay-rich MS (Figure 13). The overall characteristics were as follows: calcareous minerals were highly developed (average $46.90 \%$ ), with a large BI value (average: 0.654 ). The shale oil content was rich in well sections 3524-3551 m and well sections 3570-3598 m, with average of $2.68 \mathrm{mg} / \mathrm{g}$ and $1.27 \mathrm{mg} / \mathrm{g}$, respectively. The $3521-3552 \mathrm{~m}$ well section has included a sizable calcareous-rich shale interval with high BI, which was easy to fracture and reform. This is an optimal configuration for the development of shale oil fracturing. The well section of 3570-3598 m, with complex mineral composition, primarily included clay-rich MS and calcareous-rich MS. Calcareous MS, clay MS, and felsic MS were also developed to varying degrees. In the most-enriched shale oil area, the lithofacies were clay-rich MS with a low $\mathrm{BI}$, which was not conducive to hydraulic fracturing. However, calcareous-rich MS and calcareous MS were developed in the upper and lower parts, which were relatively brittle overall and can be used as alternative fracturing intervals.
The profile connected by wells is located in the Zhaohuangzhuang-Suning area of the Raoyang Sag (Figure 1). The middle part of the profile is located at the center of the sag, with a stable depositional environment (Figure 14). Multiple lithofacies appear alternately, including clay MS, felsic MS, felsic-rich MS, and calcareous MS. The left slope zone of the profile is close to the sediment provenance and exhibited a transitional trend. Felsic-rich MS with low shale oil content dominate the upper part of this area. A large section of calcareous-rich MS, with rich shale oil content and continuous distribution, exists in the middle and lower parts, representing good areas for shale oil development.

\section{Conclusions}

(1) The lithofacies of $\mathrm{Es}_{1}{ }^{\mathrm{L}}$ were divided into six types. Calcareous-rich MS and calcareous MS had layered structures and developed OM. The laminated clay MS had a high TOC value. The clay-rich MS, felsic-rich MS, and felsic MS primarily had massive structures and low TOC

(2) Minerals such as quartz, feldspar, calcite, and dolomite in the $\mathrm{Es}_{1}{ }^{\mathrm{L}}$ of the Raoyang Sag positively contributed to the shale brittleness. In contrast, clay and OM had an adverse effect on shale brittleness. The BP neural network mineral calculation model can better predict the continuous distribution of the lengthwise mineral composition of MS. The lengthwise distribution of the brittleness of the entire well can be obtained

(3) Lithofacies with high brittle mineral contents and developed laminae exhibited better brittleness. Although OM is a plastic substance, a high TOC value is a prerequisite for shale oil development. Therefore, calcareous-rich MS and calcareous MS 
are the dominant lithofacies for shale oil development in the $\mathrm{Es}_{1}{ }^{\mathrm{L}}$ in the Raoyang Sag. Their enrichment area can be considered as hydraulic fracturing area for shale oil reservoirs

\section{Data Availability}

The data used to support the findings of this study are included within the article.

\section{Conflicts of Interest}

The authors declare that they have no conflicts of interest.

\section{Acknowledgments}

This work was financially supported by the National Natural Science Foundation (41972123, 41922015).

\section{References}

[1] W. Zhao, S. Hu, L. Hou et al., "Types and resource potential of continental shale oil in China and its boundary with tight oil," Petroleum Exploration and Development, vol. 47, no. 1, pp. 111, 2020.

[2] S. Hu, W. Zhao, L. Hou et al., "Development potential and technical strategy of continental shale oil in China," Petroleum Exploration and Development, vol. 47, no. 4, pp. 877-887, 2020.

[3] J. Li, Z. Yang, S. Wu, and S. Pan, "Key issues and development direction of petroleum geology research of source rock strata in China," Advances in Geo-Energy Research, vol. 5, no. 2, pp. 121-126, 2021.

[4] R. P. Reid, P. T. Visscher, A. W. Decho et al., "The role of microbes in accretion, lamination and early lithification of modern marine stromatolites," Nature, vol. 406, no. 6799, pp. 989-992, 2000.

[5] Z. Jiang, D. Chen, L. Qiu, H. Liang, and J. Ma, "Source-controlled carbonates in a small Eocene half-graben lake basin (Shulu Sag) in central Hebei Province, North China," Sedimentology, vol. 54, no. 2, pp. 265-292, 2007.

[6] A. C. Aplin and J. H. S. Macquaker, "Mudstone diversity: origin and implications for source, seal, and reservoir properties in petroleum systems," AAPG Bulletin, vol. 95, no. 12, pp. 2031-2059, 2011.

[7] Y. A. N. G. Zhi, Z. O. U. Caineng, W. U. Songtao et al., "Formation, distribution and resource potential of the "sweet areas (sections)" of continental shale oil in China," Marine and Petroleum Geology, vol. 102, pp. 48-60, 2019.

[8] W. Li, J. Li, S. Lu et al., "Evaluation of gas-in-place content and gas-adsorbed ratio using carbon isotope fractionation model: a case study from Longmaxi shales in Sichuan Basin, China," International Journal of Coal Geology, vol. 249, article 103881, 2022.

[9] C. Zou, Z. Yang, J. Cui et al., "Formation mechanism, geological characteristics and development strategy of nonmarine shale oil in China," Petroleum Exploration and Development, vol. 40, no. 1, pp. 15-27, 2013.

[10] G. E. King and A. Corporation, "60 years of multi-fractured vertical, deviated and horizontal wells what have we learned," in Paper presented at the SPE Annual Technical Conference and Exhibition, Amsterdam Netherlands, 2014.

[11] K. Elwegaa and H. Emadi, "The effect of thermal shocking with nitrogen gas on the porosities, permeabilities, and rock mechanical properties of unconventional reservoirs," Energies, vol. 11, no. 8, p. 2131, 2018.

[12] A. Mahmoud, A. Gowida, M. S. Aljawad, M. al-Ramadan, and A. F. Ibrahim, "Advancement of hydraulic fracture diagnostics in unconventional formations," Geofluids, vol. 2021, 17 pages, 2021.

[13] U. C. Iyare, O. O. Blake, and R. Ramsook, "Fracability evaluation of the upper Cretaceous Naparima Hill Formation, Trinidad," Journal of Petroleum Science and Engineering, vol. 208, article 109599, 2022.

[14] G. Cui, W. Wang, B. Dou et al., "Geothermal energy exploitation and power generation via a single vertical well combined with hydraulic fracturing," Journal of Energy Engineering, vol. 148, no. 1, p. Article 04021058, 2022.

[15] K. K. Chong, B. Grieser, O. Jaripatke, and A. Passman, "A completions roadmap to shale-play development a review of successful approaches toward shale-play stimulation in the last two decades," in Paper presented at the Society of Petroleum Engineers, Beijing China, 2010.

[16] R. Rickman, M. J. Mullen, J. Petre, B. Grieser, and D. Kundert, "A practical use of shale petrophysics for stimulation design optimization all shale plays are not clones of the Barnett Shale," in Paper Presented at the SPE Annual Technical Conference \& Exhibition, Denver, Colorado, USA, 2008.

[17] L. M. Labani and R. Rezaee, "The importance of geochemical parameters and shale composition on rock mechanical properties of gas shale reservoirs a case study from the Kockatea Shale and Carynginia Formation from the Perth Basin, Western Australia," in Paper Presented at the Rock Mechanics \& Rock Engineering, Verlag Wien, 2015.

[18] D. M. Jarvie, R. J. Hill, T. E. Ruble, and R. M. Pollastro, "Unconventional shale-gas systems: the Mississippian Barnett Shale of north-central Texas as one model for thermogenic shale-gas assessment,” AAPG Bulletin, vol. 91, no. 4, pp. 475-499, 2007.

[19] F. P. Wang and J. F. Gale, "Screening criteria for shale-gas systems," Gulf Coast Association of Geological Societies Transcations, vol. 59, pp. 779-793, 2009.

[20] X. Jin, N. S. Shah, J. Roegiers, and B. Zhang, "Fracability evaluation in shale reservoirs-_an integrated petrophysics and geomechanics approach," in Paper presented at the Proceedings of the Society of Petroleum Engineers (SPE) Hydraulic Fracturing Technology Conference, Woodlands, Texas, USA, 2014.

[21] T. Guo, S. Zhang, H. Ge, X. Wang, X. Lei, and B. Xiao, “A new method for evaluation of fracture network formation capacity of rock," Fuel, vol. 140, pp. 778-787, 2015.

[22] Z. H. Jinzhou, X. U. Wenjun, L. I. Yongming, H. Jinyang, and L. Jinqin, "A new method for fracability evaluation of shale-gas reservoirs," Natural Gas Geoscience, vol. 26, no. 6, pp. 11651172, 2015.

[23] M. S. Ameen, B. G. D. Smart, J. M. Somerville, S. Hammilton, and N. A. Naji, "Predicting rock mechanical properties of carbonates from wireline logs (a case study: Arab-D reservoir, Ghawar field, Saudi Arabia)," Marine and Petroleum Geology, vol. 26, no. 4, pp. 430-444, 2009.

[24] D. A. V. Stow, A.-Y. Huc, and P. Bertrand, "Depositional processes of black shales in deep water," Marine and Petroleum Geology, vol. 18, no. 4, pp. 491-498, 2001. 
[25] Z. X. Jiang, C. Liang, J. Wu et al., "Several issues in sedimentological studies on hydrocarbon-bearing fine-grained sedimentary rocks," Acta Petrolei Sinica, vol. 34, no. 6, pp. 1031-1039, 2013.

[26] C. Liang, Z. Jiang, Y. Yang, and X. Wei, "Shale lithofacies and reservoir space of the Wufeng-Longmaxi Formation, Sichuan Basin, China," Petroleum Exploration and Development, vol. 39, no. 6, pp. 736-743, 2012.

[27] M. Opuwari and N. Dominick, "Sandstone reservoir zonation of the north-western Bredasdorp Basin South Africa using core data," Journal of Applied Geophysics, vol. 193, p. 104425, 2021.

[28] P. Zhang, S. Lu, Z. Zeng et al., "Pore structure and fractal character of lacustrine oil-bearing shale from the Dongying Sag, Bohai Bay Basin, China," Geofluids, vol. 2021, 19 pages, 2021.

[29] T. He, S. Lu, W. Li et al., "Paleoweathering, hydrothermal activity and organic matter enrichment during the formation of earliest Cambrian black strata in the northwest Tarim Basin, China," Journal of Petroleum Science and Engineering, vol. 189, article 106987, 2020.

[30] Y. Wei, X. Li, R. Zhang et al., "Influence of a paleosedimentary environment on shale oil enrichment: a case study on the Shahejie Formation of Raoyang Sag, Bohai Bay Basin, China," Earth Science, vol. 9, article 736054, 2021.

[31] W. Li, S. Lu, J. Li et al., "Carbon isotope fractionation during shale gas transport: mechanism, characterization and significance," Science China Earth Sciences, vol. 63, no. 5, pp. 674689, 2020.

[32] Q. Feng, S. Xu, X. Xing, W. Zhang, and S. Wang, "Advances and challenges in shale oil development: a critical review," Advances in Geo-Energy Research, vol. 4, no. 4, pp. 406-418, 2020.

[33] J. Li, "Development of adsorption ratio equation and state equation of liquid and their geological significance," Capillarity, vol. 4, no. 4, pp. 63-65, 2021.

[34] W. Li, S. Lu, J. Li et al., "Geochemical modeling of carbon isotope fractionation during methane transport in tight sedimentary rocks," Chemical Geology, vol. 566, article 120033, 2021.

[35] Y. Wei, J. Li, Y. du et al., "Classification evaluation of gas shales based on high-pressure mercury injection: a case study on Wufeng and Longmaxi formations in Southeast Sichuan, China," Energy \& Fuels, vol. 35, no. 11, pp. 9382-9395, 2021.

[36] E. Wang, G. Chen, H. Li et al., "Pore structure, fractal features, and oil content evaluation of lacustrine shale: a case study of first member of Paleogene Shahejie Formation, NE China," Geofluids, vol. 2021, 16 pages, 2021.

[37] Z. Jiang, W. Zhang, C. Liang, Y. Wang, H. Liu, and X. Chen, "Basic characteristics and evaluation of shale oil reservoirs," Petroleum Research, vol. 1, no. 2, pp. 149-163, 2016.

[38] S. Chen, S. Zhang, Y. Wang, and M. Tan, "Lithofacies types and reservoirs of Paleogene fine-grained sedimentary rocks Dongying Sag, Bohai Bay Basin, China," Petroleum Exploration and Development, vol. 43, no. 2, pp. 218-229, 2016.

[39] G. Wang, Z. Xiong, and J. Zhang, "The impact of lithology differences to shale fracturing," Journal of Jilin University, vol. 46, no. 4, pp. 1080-1089, 2016.

[40] F. Chen, Q. Zheng, S. Lu, X. Ding, Y. Ju, and H. Zhao, “Classification of the tight oil reservoir storage space in the Raoyang Sag of the Jizhong Depression in the Bohai Bay Basin, China," Energy Science and Engineering, vol. 8, no. 1, p. 74, 2020.

[41] J. Yin, F. Hao, Z. Wang, X. Chen, and H. Zou, "Lacustrine conditions control on the distribution of organic-rich source rocks: an instance analysis of the lower 1st member of the Shahejie Formation in the Raoyang Sag, Bohai Bay Basin," Journal of Natural Gas Science and Engineering, vol. 78, p. 103320, 2020.

[42] H. Liu, Y. Wang, Y. Jiang, F. Yuan, K. Chen, and Z. Guo, "Quantification models of overpressuring in Paleogene source rocks of the Raoyang Depression, Bohai Bay Basin, China," Marine and Petroleum Geology, vol. 109, pp. 607-622, 2019.

[43] J. Li, S. Lu, H. Xue, L. Xie, and P. Zhang, "Quantitative evaluation on the elastic property of oil-bearing mudstone/shale from a Chinese continental basin," Energy Exploration \& Exploitation, vol. 33, no. 6, pp. 851-868, 2015.

[44] S. Lu, W. Huang, F. Chen et al., "Classification and evaluation criteria of shale oil and gas resources: discussion and application," Petroleum Exploration and Development, vol. 39, no. 2, pp. 268-276, 2012.

[45] R. Altindag, "The evaluation of rock brittleness concept on rotary blast hold drills," Journal of the South African Institute of Mining and Metallurgy, vol. 102, no. 1, pp. 61-66, 2002.

[46] S. Kahraman, "Correlation of TBM and drilling machine performances with rock brittleness," Engineering Geology, vol. 65, no. 4, pp. 269-283, 2002.

[47] Z. Fan, C. Lin, T. Wang, and X. Ge, "Logging optimization modeling on brittleness index of tight formation rocks," Acta Petrolei Sinica, vol. 36, no. 11, pp. 1411-1420, 2015.

[48] H. L. Matthews, G. W. Schein, and M. R. Malone, "Stimulation of gas shales: they're all the same-right?," in Paper Presented at the SPE Hydraulic Fracturing Technology Conference, College Station, Texas, USA, 2007.

[49] M. Eliyahu, S. Emmanuel, R. J. Day-Stirrat, and C. I. Macaulay, "Mechanical properties of organic matter in shales mapped at the nanometer scale," Marine and Petroleum Geology, vol. 59, pp. 294-304, 2015.

[50] J. Yu, W. Yao, K. Duan, X. Liu, and Y. Zhu, "Experimental study and discrete element method modeling of compression and permeability behaviors of weakly anisotropic sandstones," International Journal of Rock Mechanics and Mining Sciences, vol. 134, article 104437, 2020.

[51] Y. Li, S. Wang, L. Zheng, S. Zhao, and J. Zuo, "Evaluation of the fracture mechanisms and criteria of bedding shale based on three-point bending experiment," Engineering Fracture Mechanics, vol. 255, article 107913, 2021.

[52] G. Cui, F. Ning, B. Dou, T. Li, and Q. Zhou, "Particle migration and formation damage during geothermal exploitation from weakly consolidated sandstone reservoirs via water and $\mathrm{CO}_{2}$ recycling," Energy, vol. 240, p. 122507, 2021.

[53] S. P. Morgan and H. H. Einstein, "Cracking processes affected by bedding planes in Opalinus shale with flaw pairs," Engineering Fracture Mechanics, vol. 176, pp. 213-234, 2017.

[54] Y. Wang, C. Li, J. Hao, and R. Zhou, "X-ray microtomography for investigation of meso-structural changes and crack evolution in Longmaxi formation shale during compressive deformation," Journal of Petroleum Science and Engineering, vol. 164, pp. 278-288, 2018.

[55] W. Zhang, D. Zhang, and J. Zhao, "Experimental investigation of water sensitivity effects on microscale mechanical behavior of shale," International Journal of Rock Mechanics, vol. 145, article 104837, 2021.

[56] A. Adeyilola, S. Nordeng, C. Onwumelu, F. Nwachukwu, and T. Gentzis, "Geochemical, petrographic and petrophysical characterization of the Lower Bakken Shale, Divide County, 
North Dakota," International Journal of Coal Geology, vol. 224, p. 103477, 2020.

[57] L. O. Lawal, M. Mahmoud, A. Adebayo, and A. Sultan, "Brittleness and microcracks: a new approach of brittleness characterization for shale fracking," Journal of Natural Gas Science and Engineering, vol. 87, article 103793, 2021.

[58] K. Hornik, M. Stinchcombe, and H. White, "Multilayer feedforward networks are universal approximators," Neural Networks, vol. 2, no. 5, pp. 359-366, 1989.

[59] H. Chen, Y. Wang, M. Zuo et al., "A new prediction model of $\mathrm{CO}_{2}$ diffusion coefficient in crude oil under reservoir conditions based on BP neural network," Energy, vol. 239, p. 122286, 2022.

[60] D. Wu, D. Zhang, S. Liu et al., "Prediction of polycarbonate degradation in natural atmospheric environment of China based on BP-ANN model with screened environmental factors," Chemical Engineering Journal, vol. 399, article 125878, 2020.

[61] J. Jawad, A. H. Hawari, and S. Javaid Zaidi, "Artificial neural network modeling of wastewater treatment and desalination using membrane processes: a review," Chemical Engineering Journal, vol. 419, article 129540, 2021.

[62] Q. Yasin, Q. Du, G. M. Sohail, and A. Ismail, "Fracturing index-based brittleness prediction from geophysical logging data: application to Longmaxi shale," Geomechanics and Geophysics for Geo-Energy and Geo-Resources, vol. 4, no. 4, pp. 301-325, 2018. 